\title{
A TUNABLE FEMTOSECOND STIMULATED RAMAN SCATTERING SYSTEM BASED ON SPECTRALLY NARROWED SECOND HARMONIC GENERATION
}

\author{
K. Redeckas, V. Voiciuk, and M. Vengris \\ Department of Quantum Electronics, Vilnius University, Sauletekio 10, LT-10223 Vilnius, Lithuania \\ E-mail: kipras.redeckas@ff.vu.lt
}

Received 13 November 2015; revised 6 January 2016; accepted 25 March 2016

\begin{abstract}
In this work we present a femtosecond stimulated Raman scattering system. The setup is based on a commercial femtosecond laser system supplemented by a pair of travelling-wave optical parametric amplifiers. One of the parametric amplifiers is used to generate the femtosecond actinic pump pulses, whereas the output of the other (high-power) parametric amplifier undergoes a combination of spectrally narrowed second harmonic generation in a long non-linear crystal and subsequent spectral filtering for the generation of narrowband Raman pump pulses. Chirped white light supercontinuum is used as the Raman probe. The setup offers tunability of the Raman pump pulses in the 400-800 nm range, and spectral and temporal resolutions of ca. $6 \mathrm{~cm}^{-1}$ and ca. $70 \mathrm{fs}$, respectively. We present the basic technical and optical aspects of the system along with data acquisition and signal retrieval techniques. We characterize the system by exploring the time-resolved vibrational dynamics of the $\mathrm{S}_{2}\left(1^{1} \mathrm{~B}_{\mathrm{u}}^{+}\right)$and $\mathrm{S}_{1}\left(2^{1} \mathrm{~A}_{\mathrm{g}}^{-}\right)$excited states of $\beta$-carotene.
\end{abstract}

Keywords: femtosecond stimulated Raman scattering, FSRS, ultrafast vibrational spectroscopy, carotenoids, $\beta$-carotene PACS: 07.60.Rd, 42.65.Dr, 31.70.Hq

\section{Introduction}

Time-resolved vibrational spectroscopy is a powerful experimental tool for identifying and characterizing the molecular motions taking place as a result of electronic excitation. High-resolution spectral information on the vibrational coordinates of the photoreaction can give additional insight on the photodynamics, which is normally lost on conventional (electronic) UV-nIR transient absorption experiments. Contemporary commercial or home-built femtosecond laser systems, equipped with broadband tunable UV-to-mid-IR parametric devices, facilitate the technical design aspects of high spectro-temporal resolution UV-VIS pump/ mid-IR probe spectroscopic experiments. While these techniques have been the staple of one-dimensional vibrational pump-probe spectroscopy for a long time [1, 21, they often suffer from such drawbacks as a limited bandwidth of the probing radiation, low parametric conversion efficiency and stability of the long-wavelength $(\geq 10 \mu \mathrm{m})$ radiation, high cost and low resolution of typically employed HgCdTe sensors and IRdesignated optics. To circumvent the latter problem, frequency upconversion techniques have been recently suggested as an alternative [3, 4 . However, other experimental inconveniences, such as the requirement of gas-purged chambers for the IR probe, the necessity of high sample concentrations (due to low extinction coefficients of vibrational transitions), and the difficulty of measuring samples in solutions (especially aqueous), hinder the time-resolved IR measurements.

Femtosecond stimulated Raman scattering (FSRS) spectroscopy [5-7] is a relatively recent, yet moderately widespread time-resolved spectroscopic method. Since its inception in the early 2000's [6-8], FSRS techniques have been utilized to investigate various photobiological pigments [9-13], compounds that undergo photo-isomerization [14-16], metalorganic molecules [17, 18], donor-acceptor systems [19-22], etc. During its development numerous spin-off FSRS techniques, such as impulsive FSRS [23], femtosecond Raman-induced Kerr effect spectroscopy (FRIKES) [24], surface-enhanced FSRS 25,, two-dimensional FSRS in the impulsive limit [26, 27], chirped-pulse FSRS [28], and even FSRS with quantum-entangled light [29], have been both theoretically suggested and experimentally implemented. At its core, FSRS, as depicted in Fig. 1, is a multi-pulse technique that can be summarized as follows. An ultrashort actinic pulse (1 in Fig. 1) acts on a molecular system in its ground state $|g, 0\rangle\langle g, 0|$ (the first symbol denotes electronic and the second one denotes vibrational quantum number) and 


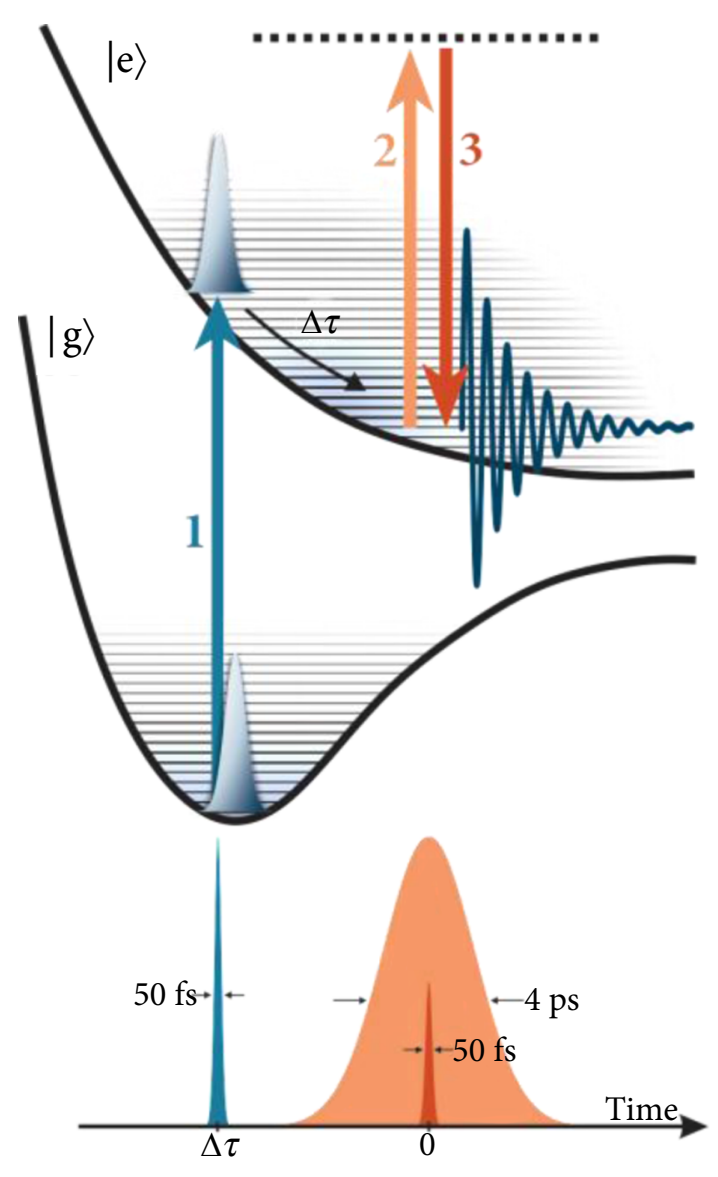

Fig. 1. A simplified scheme of the FSRS process within a two-level vibronic system. A femtosecond actinic pulse (1)excites a molecular system, while a pair of synchronized narrowband Raman pump (2) and broadband Raman probe (3) pulses produce a vibrational coherence in the evolving excited state, resulting in the emission of Stokes (and anti-Stokes) photons on top of the probe field [5].

initiates the photoreaction by preparing a wavepacket in the excited state $|e, n\rangle\langle e, n|$. A pair of temporally delayed pulses probes the successive photoevolution. An intense narrowband (picosecond) pulse (2 in Fig. 1) triggers Raman scattering within the evolving system. The scattering process is predominantly incoherent prior to the arrival of a broadband ultrashort probe pulse (3 in Fig. 1). A temporal overlap of these two pulses brings about a coherence in the excited (or the eventual photoproduct) state $|e, n\rangle\langle e, m \neq n|$, resulting in the amplification of the Stokes and antiStokes frequencies within the probe field (i. e. stimulated Raman emission). Since a high degree of coherence is achieved only during the short temporal overlap of the Raman pump and probe pulses, FSRS spectroscopy offers both good spectral $\left(\Delta v \leq 5 \mathrm{~cm}^{-1}\right.$, limited by the bandwidth of the Raman pump pulse and capabilities of the imaging optics) and temporal
( $\Delta \tau \leq 50 \mathrm{fs}$, limited by the duration of the actinic and probe pulses) resolution, without violating the Heisenberg uncertainty principle [5, 30, 31]. Furthermore, many of the drawbacks of conventional mid-IR transient absorption spectroscopy mentioned above are circumvented in FSRS, because the vibrational experiment is reallocated to the VIS-nIR domain, where both the lasers and the detectors perform significantly better. In this paper we present a home-built tunable FSRS setup, in which the generation of narrowband Raman pump pulses is based on the spectral narrowing of femtosecond pulses via propagation through a long nonlinear crystal (along with further refinement via spectral filtration). We showcase the features, capabilities, and limitations of the said FSRS system. Additionally, we demonstrate a practical application of the presented setup by measuring the time resolved FSRS spectra of $\beta$-carotene by exploiting either the $S_{2} \rightarrow S_{n}$ or the $S_{1} \rightarrow S_{n}$ electronic resonances, and discuss the possible future prospects of the systems.

\section{Methods}

\subsection{Experimental setup}

\subsubsection{Actinic pump generation}

A simplified diagram of the experimental setup is presented in Fig. 2. The FSRS system is based on a commercial titanium-sapphire (Ti:Sa) Kerr lens modelocked oscillator/chirped pulse regenerative amplifier system Libra (Coherent), that provides a $1 \mathrm{kHz}$ train of $3.5 \mathrm{~mJ}, 50 \mathrm{fs}, \lambda_{0}=800 \mathrm{~nm}, \Delta \lambda_{\mathrm{FWHM}}=25 \mathrm{~nm}$ pulses. Roughly $1 /{ }_{5}$ of the laser output (ca. $\left.750 \mu \mathrm{J}\right)$ is used to pump a travelling-wave optical parametric amplifier Topas-800 (Light Conversion), achieving ca. 30\% conversion efficiency at $1300 \mathrm{~nm}$ (signal) and $2080 \mathrm{~nm}$ (idler) with $\leq 1 \% \sigma / \mu$ (i. e. standard deviation divided by the mean) pulse-to-pulse energy stability (due to gain narrowing and the inner dispersion of the OPA, the actinic pulse is prolonged up to ca. $70 \mathrm{fs}$, albeit the residual chirp is left uncompensated in the FSRS experiments). Frequency doubled, quadrupled or upconverted output of this OPA (typically in the UV or violet-to-green portion of the visible spectrum) is used as the actinic pump radiation (1 in Fig. 1) in the FSRS experiments. A phase-locked optical chopper (Stanford Research Systems SR540) periodically blocks the actinic pump beam and a synchronized photodiode monitors its blocked/opened state and the shot-to-shot energy stability (pulses with the pump energies more than $3 \sigma$ away from the mean value are omitted from the measurement). A temporal delay of the actinic pulse is realized by a $30 \mathrm{~cm}$ travel single-pass optical delay line 


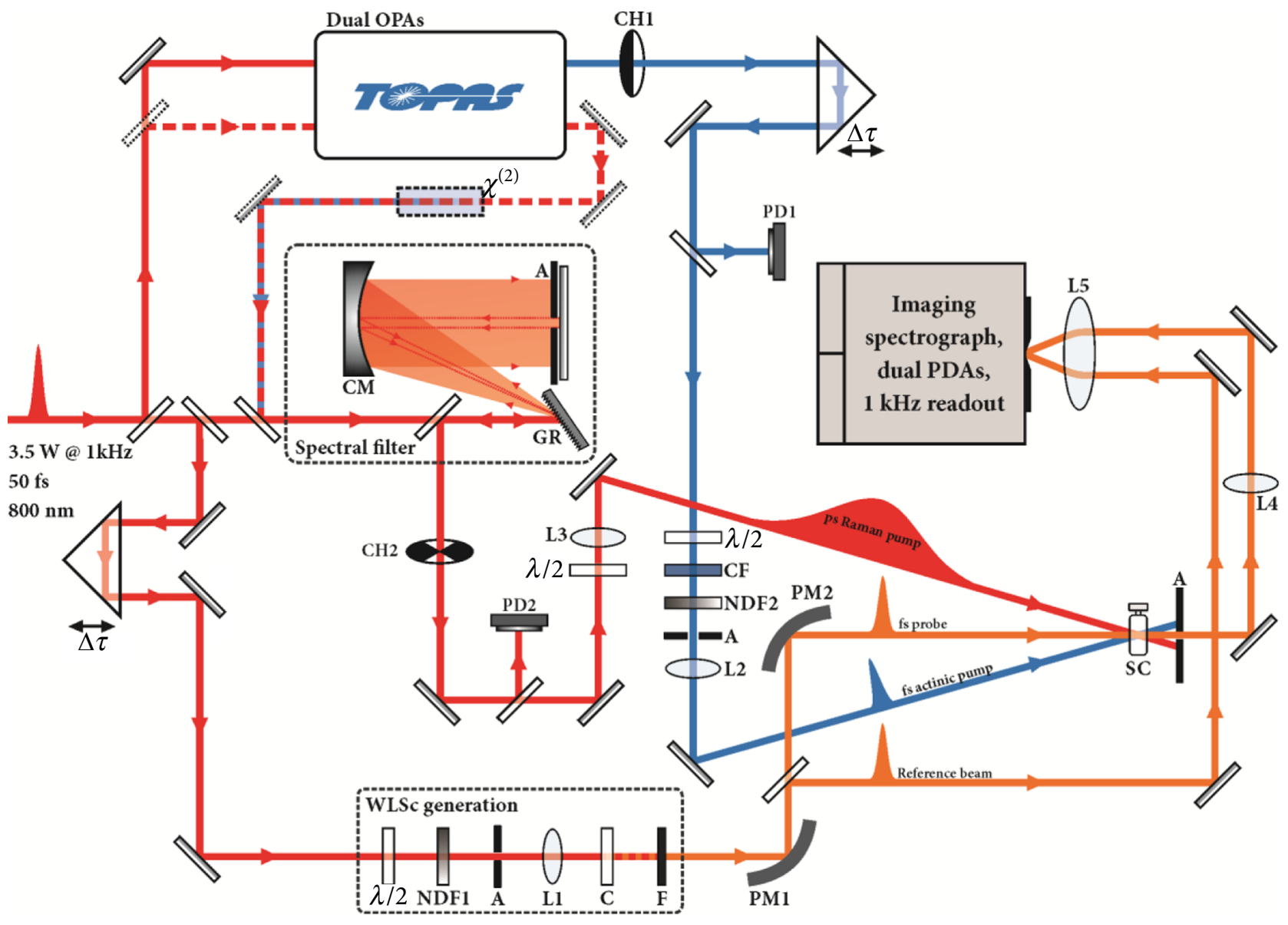

Fig. 2. A simplified layout of the FSRS apparatus. Abbreviations: A, aperture; C, WLSc generation crystal; CF, colour filter; CM, concave mirror; CHn, optical choppers; F, WLSc pump blocking (notch or coloured glass) filter; GR, diffraction grating; Ln, lenses; NDFn, neutral optical density filters; PDn, photodiodes; PMn, parabolic off-axis mirrors; SC, sample compartment; $\lambda / 2$, half-wave plates; $\chi^{(2)}$, non-linear 2 nd harmonic generation crystal (KDP).

(Aerotech ALS10030), achieving ca. 2 ns of a probe time window.

\subsubsection{Raman pump generation}

Several different approaches can be undertaken to obtain the narrowband Raman pulses ( 2 in Fig. 1) from a femtosecond laser source. The simplest (on top of being the cheapest) way of obtaining picosecond pulses is spectral filtering of the fundamental Ti:Sa radiation by a Fourier- $4 f$ filter 㱙, 32] or a spectral etalon [33, 34. Alternatively a portion of the locally-narrowband chirped output of the regenerative amplifier can be employed, though not without raising some calibration inconveniences [35, 36]. Considering the ca. $400 \mathrm{~cm}^{-1}$ bandwidth of the Libra system, spectral filtering can be effectively implemented in the nIR region of ca. 775$825 \mathrm{~nm}$ (or, alternatively, at the UV/VIS boundary of ca. $395-405 \mathrm{~nm}$ by exploiting the $2 \mathrm{nd}$ harmonic generation). The obvious drawbacks of this approach are immense energy losses (e. g. in order to obtain a Ra- man pump pulse with $5 \mathrm{~cm}^{-1}$ bandwidth, more than ca. $98 \%$ of the initial pulse energy is lost both due to filtration and diffraction/reflection losses) and the limited tunability of picosecond radiation. The most energy efficient method is, beyond doubt, the utilization of a commercial [20, 37] or a home-built [38-40] picosecond OPA, pumped by the second harmonic bandwidth compressed Ti:Sa radiation. This approach not only minimizes the energy losses, arising from the pico-to-femtosecond conversion, but also offers a broad tunability of the Raman pump pulses in the entire visible and near IR regions, which is usually desired for attaining resonant or pre-resonant conditions with the investigated molecular system. The penalty, however, is greatly increased complexity and the overall cost of the Raman pump system.

Tunability of the Raman pump is typically desired in FSRS experiments, considering that FSRS is the $\chi^{(5)}$ process and a resonant enhancement of the vibrational modes greatly increases the resolvable signal amplitude and raises it well above the electronic background 
[16, 39, 40, When designing our picosecond Raman source, we have opted for a compromise between the two above discussed approaches, enabled by high pulse energy of the current off-the-shelf Ti:Sa systems. The largest portion (ca. $1.2 \mathrm{~mJ}$ ) of the fundamental laser radiation is used to pump an additional (high-power) travelling-wave OPA Topas- 800 , achieving ca. $40 \%$ energy conversion efficiency at $1300 / 2080 \mathrm{~nm}$ (signal/ idler waves can be typically tuned in the $1150-2500 \mathrm{~nm}$ region [41]). The HP-OPA output beams are then passed through a potassium dihydrophosphate (KDP) crystal (type I, $\theta=41^{\circ}, \phi=45^{\circ}, 65 \mathrm{~mm}$ path length or type II, $\theta=58^{\circ}, \phi=0^{\circ}, 45 \mathrm{~mm}$ path length; apertures of both crystals are $20 \times 20 \mathrm{~mm}$ ), where they are either frequency-doubled, quadrupled or sum-frequency mixed with the fundamental pump radiation, thus effectively (ca. 45\% @ $650 \mathrm{~nm}$ ) frequency-shifting them into the blue-to-nIR (ca. 400-800 nm) part of the spectrum (standalone $800 \mathrm{~nm}$ pump or its $2 \mathrm{nd}$ harmonic can obviously also be utilized in this configuration, as indicated in Fig. 2). The extensive length of the crystal ensures high non-linear conversion efficiency and, because of the group velocity mismatch between the interacting beams and strict phase-matching conditions for only a certain set of wavevectors, the upconverted pulses become temporally stretched and spectrallynarrowed [42]. Due to the temporal walk-off between pulses and the constant depletion of the fundamental beam energy along the span of the lengthy non-linear medium the frequency-doubled pulses obtain an exponential temporal profile (see Fig. 3 and refs. 44, 43,). A more "usual" temporal shape (i. e. Gaussian, sech $^{2}$ or $\operatorname{sinc}^{2}$ ) can be achieved either via negatively pre-chirping the initial pulse prior to its passing through the nonlinear medium [42] or by successive spectral filtering of the second harmonic output [43]. Since the energy losses of both of these methods can be expected to be roughly the same, we have opted for the latter approach because it automatically ensures a bandwidth-limited temporal shape of the Raman pump pulse. Spectral filtering of the second harmonic of the HP-OPA was performed by a Fourier- $4 f$ filter, consisting of a $1200 \mathrm{~mm}^{-1}$ grating (blazed at either 500 or $800 \mathrm{~nm}$ ), a concave $f=+500 \mathrm{~mm}$ silver mirror, and a silver back-reflecting mirror in the Fourier plane of the $4 f$ system. An adjustable optical slit, positioned adjacent to the Fourier plane mirror, simultaneously controls the central wavelength, bandwidth and energy of the picosecond pulses. Pulses as narrow as $1.5 \mathrm{~cm}^{-1}(10 \mathrm{ps})$ can be achieved in this configuration. While ultimately FSRS gain depends on the investigated sample, from our experience from $300 \mathrm{~nJ}$ up to $5 \mu \mathrm{J}$ of Raman pump energy were typically required to achieve a good signal-to-background ratio in standard FSRS experiments (an exemplary Raman pump pulse is presented in Fig. 3(b)). A better spectral resolution can always be achieved by an increased spectral narrowing of the Raman pump pulses, albeit this leads to the linear reduction of the FSRS signal [7],
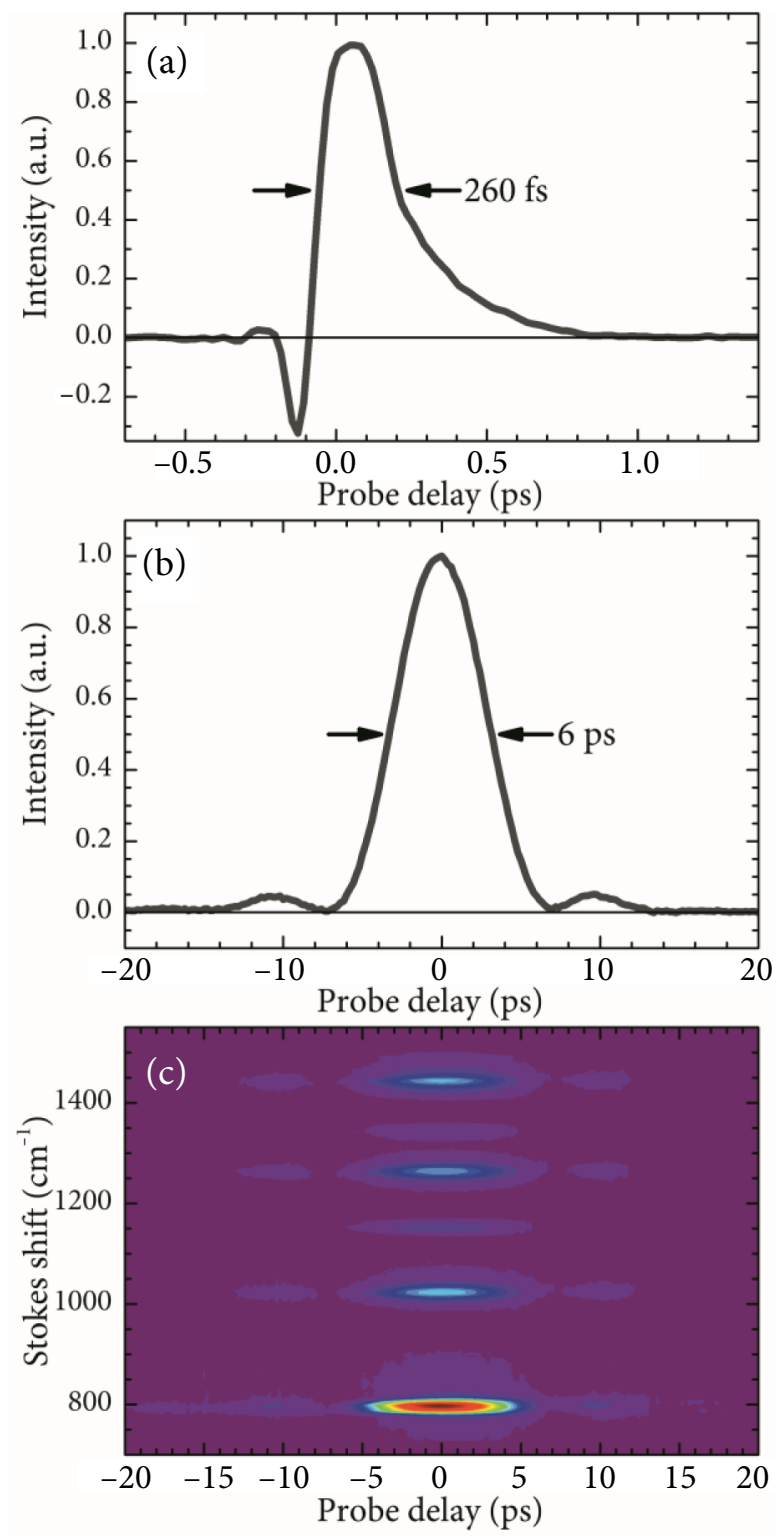

Fig. 3. Temporal Raman gain profiles of the $802 \mathrm{~cm}^{-1}$ $\mathrm{C}-\mathrm{C} \mathrm{A}_{1 \mathrm{~g}}$ stretching vibration of cyclohexane, obtained by using 2 nd harmonic temporally stretched $\left(\chi^{(2)}\right.$ in Fig. 2$)$ $\lambda_{c}=625 \mathrm{~nm}$ Raman pump pulses (a) without and (b) with the implementation of spectral filtering (a dashed rectangular box in Fig. 2). Figure (c) depicts the entire spectro-temporal cross-correlation signal (in cyclohexane) between the spectrally filtered Raman pump (b) and the ultrashort Raman probe pulses. Since $\tau_{\text {probe }} \ll \tau_{\text {Raman }}$, these intensity cross-correlation relations roughly estimate the envelope of the Raman pump pulses (note the exponential "tail" of the Raman pulses in (a) and the $\sin c^{2}$-like sidebands in (b)). 
thus disclosing that a compromise between signal strength and spectral resolution should be sought under the given experimental conditions. Second harmonic generation and spectral filtering processes do not greatly impair the stability of the OPA output, therefore the ultimate pulse-to-pulse stability of the Raman pump radiation can be achieved as high as $2 \% \sigma / \mu$. It should be also mentioned that, despite the low cost and wide commercial availability of large crystals, KDP is impaired by its limited transparency (0.2$1.6 \mu \mathrm{m})$ and low nonlinearity $\left(d_{\text {eff }} \sim 0.39 \mathrm{pm} / \mathrm{V}\right)$ [44], thus suggesting other feasible candidates for Raman pump generation, such as BBO [45]. Optical chopping and pulse stability monitoring of the Raman pump are analogous to the actinic pump branch (see above), differing only in that the optical chopping of the picosecond pulses is performed at a twice lower rate.

\subsubsection{Raman probe generation}

A white light supercontinuum (WLSc), generated by tightly focusing a small fraction (ca. 1\%) of the fundamental Libra output into a $3 \mathrm{~mm}$ thick sapphire (450$1100 \mathrm{~nm})$ or calcium fluoride $(350-1100 \mathrm{~nm})$ crystal, is used as a broadband Raman probe ( 3 in Fig. 1). The WLSc is spectrally filtered from the excessive $800 \mathrm{~nm}$ radiation, using either a custom made dielectric notch filter $\left(\lambda_{\mathrm{c}}=815 \mathrm{~nm}, \Delta \lambda_{\text {band }}=200 \mathrm{~nm}, T_{>85 \%}=300\right.$ $730 \mathrm{~nm}$ ) or a long-pass colored glass filter (Schott RG830, $\left.T_{>85 \%}=830-2700 \mathrm{~nm}\right)$. Since the Raman pump optical branch is fixed (see Fig. 2), proper temporal arrangement of Raman pump and Raman probe pulses (see Fig. 1) is achieved by precisely delaying the probe pulse (using a $60 \mathrm{~cm}$ delay line Aerotech ALS10060) to realize the highest Raman gain signal (see Fig. 3(c)). The positive chirp (ca. 600 fs between 450 and 1000 $\mathrm{nm}$, albeit significantly lower in the actual $\Delta \lambda \approx 50 \mathrm{~nm}$ probe window) is left uncompressed in order to avoid any energy losses of the weak (ca. $20 \mathrm{~nJ}$ ) probe pulses and the chirp correction is implemented purely numerically (refer to the next section). These two shortcomings can be generally overcome if a broadband tunable NOPA is used as the Raman probe instead of WLSc [39, 40].

After passing the sample ( $1 \mathrm{~mm}$ Hellma quartz cuvette), the probe beam is re-collimated and focused into an $100 \mu \mathrm{m}$-wide entrance slit of an imaging spectrograph (Oriel MS127i, focal length $127 \mathrm{~mm}$ ) and readout with a 256 pixel photodiode array (Hamamatsu S8381-256Q, pixel size $25 \mu \mathrm{m}$ ). Depending on the necessity to achieve either enhanced spectral resolution (up to $3.5 \mathrm{~cm}^{-1}$ ) or a broader Stokes shift region (up to $2000 \mathrm{~cm}^{-1}$ ) an 1200 or a $600 \mathrm{~mm}^{-1}$ diffraction grating (Thorlabs GR50-1205, GR25-1210, or GR25-0610) is appropriately used to disperse the Raman probe spectrum. The pixel-to-wavenumber calibration is typically performed by measuring the ground state FSRS spectrum of a vibrationally "rich" solvent (e. g. toluene or $n$ hexane), and by the least square fitting the spectrally-resolved signals to best match the referential Raman data (an entire temporal cross-correlation map, as the one presented in Fig. 3(c), is typically measured before or after the experiment in order to gain both the spectral calibration data and the Raman pump pulse duration).

The achievable pulse-to-pulse probe energy stability is typically good enough for any standard FSRS experiments in the VIS-to-nIR region (ca. $\leq 0.7 \% \sigma / \mu$ within the entire spectral window). The low-energy extent of the nIR domain (i. e. $820-850 \mathrm{~nm}$, which amounts to the lower-wavenumber region of $300-750 \mathrm{~cm}^{-1}$ with an $800 \mathrm{~nm}$ Raman pump) of the WLSc is notably less stable (ca. $\geq 3 \% \sigma / \mu)$ due to the more prominent self-phase modulation and the steep continuum-to-seed-pulse transition near the WLSc pump central wavelength. Therefore in the nIR detection measurements, a probe is divided into sample and reference beams, and a synchronized dual photodiode array detection system is typically employed, allowing to achieve probe stability as high as ca. $0.1 \% \sigma / \mu$. In practice, Stokes shift frequencies, ranging from ca. $100 \mathrm{~cm}^{-1}$ up to ca. $3200 \mathrm{~cm}^{-1}$, can be measured using this FSRS setup, although the uncompensated temporal chirp of the WLSc can hinder the amplitude or the spectral resolution at the highest and the lowest frequencies due to coherence loss between the Raman pump and probe pulses. The lower bound is typically affected by the Rayleigh wing scattering of the Raman pump pulse, whereas the upper limit is restricted by either the probe light instabilities in the close proximity of the WLSc pump central wavelength $(800 \pm 20 \mathrm{~nm})$ in the VIS region or the spectral sensitivity of the silicon-based PDAs in the nIR (up to ca. $1 \mu \mathrm{m})$.

All three interacting beams are polarized parallel to one another ( $p$-polarization is typically preferred) to realize the best Raman gain and signalto-noise ratio of the FSRS signals [46], albeit "magic angle" configuration is also possible. The actinic and Raman pump beams are typically focused with plano-convex UVFS lenses $(f=200-300 \mathrm{~mm})$, whereas parabolic collimating/focusing optics are used in the Raman probe branch to avoid any unnecessary pulse stretching/chirping. The Raman pump and probe beams are focused to have the smallest possible beam waist at the sample plane $\left(\varnothing_{\text {Raman }} \simeq 80 \mu \mathrm{m}, \varnothing_{\text {Probe }} \simeq 70 \mu \mathrm{m}\right.$ at FWHM), whereas the actinic pump beam is normally kept larger $\left(\varnothing_{\text {Actinic }} \simeq 120 \mu \mathrm{m}\right.$ at FWHM). Data acquisition is performed with the NI DCI-6120 data acquisition 
board and the measurement is fully automated in NI Labview 2010. A conventional FSRS experiment, consisting of approximately 150 temporal delay points, is typically performed in under 3 hours. In order to avoid sample over-exposure during the duration of the experiment, the sample cell is translated transversely to the beam propagation direction in a Lissajous pattern, using a set of two perpendicularly assembled translation stages (Standa 8MT173).

\subsection{Data manipulation and handling}

With a set of two phase-locked optical choppers, operating at $1 / 2$ and $1 / 4$ of the repetition rate of the laser system (or, alternatively, ${ }^{1}{ }_{4}$ and $1 / 8$, if a larger amount of probe light is necessary to be accumulated on the detector), four discrete sets of background-corrected sample $\left(I(\tau, v)=I_{\text {Raw }}(\tau, v)-I_{\text {Bckg }}(\tau, v)\right.$ and reference $\left(R(\tau, v)=R_{\text {Raw }}(\tau, v)-R_{\text {Bckg }}(\tau, v)\right)$ data are collected per trigger event. Under these conditions the entire timeand wavenumber-resolved FSRS gain spectrum (in dimensionless mOD units) can be expressed as

$$
\begin{aligned}
& \Phi^{(0)}(\tau, v)=1000 \cdot \log _{10}\left(\left(\frac{I_{11}(\tau, v)}{R_{11}(\tau, v)} \cdot \frac{I_{00}(\tau, v)}{R_{00}(\tau, v)}\right) /\right. \\
& \left.\left(\frac{I_{01}(\tau, v)}{R_{01}(\tau, v)} \cdot \frac{I_{10}(\tau, v)}{R_{10}(\tau, v)}\right)\right)
\end{aligned}
$$

and the ground state FSRS gain as

$$
\begin{aligned}
& \Gamma^{(0)}(\tau, v)=1000 \cdot \log _{10}\left(\left(\frac{I_{01}(\tau, v)}{R_{01}(\tau, v)}\right) /\right. \\
& \left.\left(\frac{I_{00}(\tau, v)}{R_{00}(\tau, v)}\right)\right)
\end{aligned}
$$

where the subscript indices indicate an open/blocked state of the actinic pump (1st index) and the Raman pump (2nd index). As a whole, the ground state FSRS spectrum does not depend on the actinic pump delay $\tau$. This implies that FSRS measurements can be performed without modulating the Raman pump beam [4, 47, (i. e. only registering the temporal changes of the Raman gain spectrum with and without the actinic pump). However, modulating both beams has its merits: it simultaneously provides the conventional pump-probe data

$$
\begin{aligned}
& \Pi(\tau, v)=1000 \cdot \log _{10}\left(\left(\frac{I_{10}(\tau, v)}{R_{10}(\tau, v)}\right) /\right. \\
& \left.\left(\frac{I_{00}(\tau, v)}{R_{00}(\tau, v)}\right)\right)
\end{aligned}
$$

and allows monitoring fluctuations and drift of the ground state Raman gain during the measurement.

Both of the aforementioned signals $\Phi$ and $\Gamma$ contain a smooth continuous baseline, that appears either from stimulated emission, various higher- or lower-order non-linear $\left(\chi^{(3)}, \chi^{(5)}\right.$, etc.) non-FSRS interactions between the pulses [31], pump-dump depletion (sometimes referred as Raman-induced by non-linear emission (RINE) [13]), or pump-repump induced absorption effects on the transient species. It is possible to diminish the baseline contribution by using the Raman pump wavelength modulation [22, 38, 48, 49, however, most of these methods, nonetheless, require heavy FSRS signal post-processing in order to "flatten-out" the final transient spectrum. As in several previously described approaches [9, 11, 20, 50], we have opted to reconstruct the time-resolved baseline and solvent Raman line free FSRS signal by using a data handling algorithm, which is depicted in Fig. 4 and can be summarized as follows:

1. Temporal chirp of the probe pulse is estimated by the rise of the pump probe signal $\Pi(\tau, v)$ in the interval $-1 \mathrm{ps} \leq \tau_{i} \leq 1 \mathrm{ps}$, the dispersion is approximated by a polynomial curve $\left(N_{\text {Poly }} \geq 4\right)$ and the kinetic signals are appropriately shifted and interpolated along a fixed temporal axis (see Fig. 4(a)). The halfrise point of the $\Delta \mathrm{OD}$ signal is typically designated as the "actual" zero moment, albeit in some cases, i. e. when the appearance of transient absorption is not entirely IRF-limited, a more precise evaluation is required.

2. The pre-actinic pump (i. e. $\tau \leq-1$ ps) FSRS spectrum is averaged over temporal delay points and subtracted from the FSRS dataset:

$$
\Phi^{(1)}(\tau, v)=\Phi(\tau, v)-\sum_{\tau_{i} \leq-1} \frac{\Phi\left(\tau_{i}, v\right)}{N_{\tau_{i \leq-1}}} .
$$

This removes (or lessens) the solvent Raman line artifacts, remaining in the FSRS signal.

3. A set of baseline-defining points (i. e. a constant number $N \geq 10$ of spectral points that exhibit insignificant Raman gain and only outline the baseline signal) is chosen manually for both FSRS and ground state FSRS signals (red dots online in Fig. 4(b)) and the baseline is approximated by a cubic spline curve, passing through these zero-intersection points. Alternatively, a peak-isolation method can be employed, in which a set of $N$ points (where $N$ is a multiple of 2 ) is used to define the peak or peak cluster locations (ith point signifying the "beginning" of a single particular peak region, and the $(i+1)$ th point signifying the "end" of the peak region). All of the remaining 


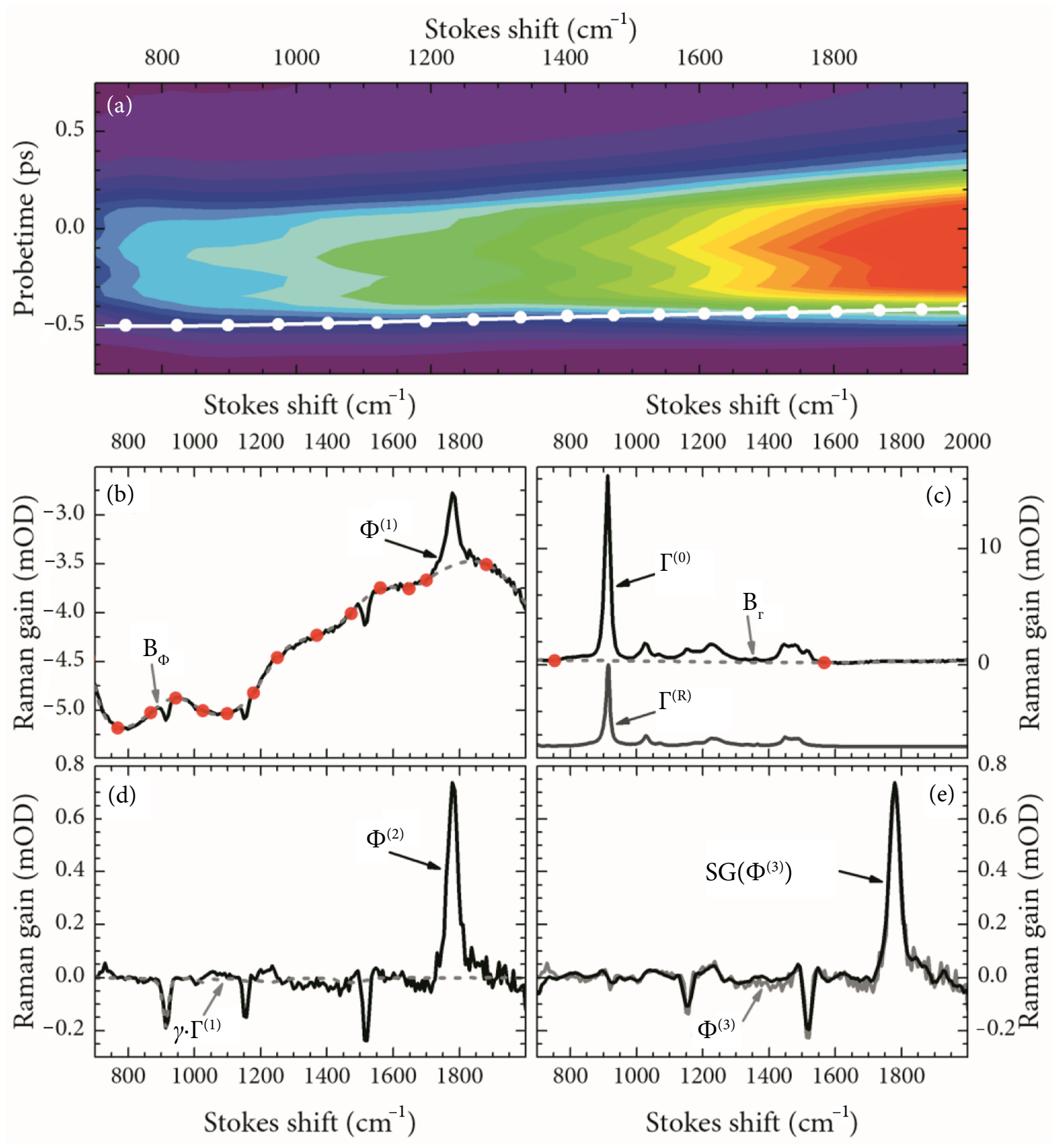

Fig. 4. FSRS signal recovery procedure for $\beta$-carotene in THF $\left(\lambda_{\mathrm{AP}}=490 \mathrm{~nm}, E_{\mathrm{AP}}=150 \mathrm{~nJ}, \tau_{\mathrm{AP}}=70 \mathrm{fs} ; \lambda_{\mathrm{RP}}=790 \mathrm{~nm}\right.$, $E_{\mathrm{RP}}=3 \mu \mathrm{J}, \tau_{\mathrm{RP}}=6 \mathrm{ps}$ ): (a) Raman probe dispersion correction according to the pump-probe signal (Eq. (3)); (b) separation of signal and background components for the "pure" FSRS signal (Eq. (5)); (c) separation of signal and background components for the solvent/ground state FSRS signal (Eq. (6)); (d) removal of the solvent/ground state FSRS contribution (Eq. (7)); (e) noise suppression via Savitzky-Golay filtering. Refer to the main text for more details.

(i. e. "non-peak") points are then assumed to represent only the baseline and are approximated by a high order $(\geq 5)$ polynomial curve (this method is applied in Fig. $4(\mathrm{c})$ ). The baselines $B_{\Phi}(v)$ and $B_{\Gamma}(v)$ (dashed gray curves in Fig. $\left.\Phi_{(}(\mathrm{b}, \mathrm{c})\right)$ are then calculated according to the chosen method for each temporal point, re- sulting in two baseline matrices, $B_{\Phi}(\tau, v)$ and $B_{\Gamma}(\tau, v)$. These are then subtracted from the FSRS and ground state FSRS spectra:

$$
\Phi^{(2)}(\tau, v)=\Phi^{(1)}(\tau, v)-B_{\Phi}(\tau, v)
$$




$$
\Gamma^{(1)}(\tau, v)=\Gamma^{(0)}(\tau, v)-B_{\Gamma}(\tau, v) .
$$

It should be noted that if any significant spectral shifts occur throughout the spectral evolution (e. g. as in the theoretical illustration of Ref. [51]), a careful reassessment of the zero-intersection points at different temporal windows is necessary in order not to distort the resulting FSRS dynamics.

4. At each delay point, a scaled ground state FSRS signal is subtracted from the excited state FSRS signal in order to diminish any residual solvent vibrational lines in the final FSRS spectrum

$$
\Phi^{(3)}\left(\tau_{i}, v\right)=\Phi^{(2)}\left(\tau_{i}, v\right)-\gamma_{i} \cdot \Gamma^{(1)}\left(\tau_{i}, v\right),
$$

where $\gamma_{i}$ is the scaling factor, based on the amplitude of the largest residual solvent Raman peak in each individual $\Phi^{(2)}\left(\tau_{i}, v\right)$ (e. g. in Fig. $4(\mathrm{~d}) \gamma$ is determined by the amplitude of the $913.1 \mathrm{~cm}^{-1}$ Raman line of THF [52]). It should be emphasized that $\Gamma(1)$ should be meticulously checked for ground state FSRS signals of the investigated sample prior the subtraction, e. g. ground state FSRS contribution of $\beta$-carotene under off-resonant (i. e. $v_{\mathrm{RP}}<<v_{\mathrm{S}_{0} \rightarrow \mathrm{S}_{n>>}}$ ) conditions is minimal (i. e. the pure THF FSRS signal is more than $15 \times$ more intense than that of $\beta$-carotene in Fig. $4($ (c)), thus (7) can be performed without greatly distorting the original data. Otherwise, if the contributions of sample and solvent FSRS signals are comparable, an independently measured pure solvent FSRS reference $\left(\Gamma^{(R)}(v)\right.$ in Fig. 4(c)) should, preferably, be used as a replacement for $\Gamma^{(1)}\left(\tau_{\vec{i}}, v\right)$ in (7). The remaining negative Raman lines of the sample (i. e. ground state Raman line bleaching) can be removed in a similar fashion, with the aim of amassing only the Raman gain (and not the Raman loss) spectrum [11, 12, 53], though we have chosen to leave the Raman bleaching contribution intact in our FSRS spectra.

5. A Savitzky-Golay filter (variable, albeit a 4th order polynomial within a 6 point window is typically used) is applied to each $\Phi^{(3)}\left(\tau_{i}, v\right)$ in the dataset to reduce the pixel-to-pixel noise, if necessary (Fig. A(e)).

The FSRS data management is performed using the homemade software, written in C++ with Qt 5.4 framework and the QCustomPlot library for graph visualization.

\section{Application example: FSRS spectra $\beta$-carotene}

Carotenoids are some of the most widespread and important pigments in nature that are responsible for both the light-harvesting and photo-protective functions of the photosynthetic apparatus [54-56. The molecular backbone of carotenoids is composed of an extensive conjugated $\pi$-electron system that effectively defines their spectroscopic properties. The high degree of symmetry of the $\pi$-electron system ascribes carotenoids to the $\mathrm{C}_{2 \mathrm{~h}}$ symmetry point group, thus directly prohibiting electronic transitions between the ground state and the lowest lying singlet electronic state $\left(\mathrm{S}_{0}\left(1^{1} \mathrm{~A}_{\mathrm{g}}^{-}\right) \nrightarrow \mathrm{S}_{1}\left(2^{1} \mathrm{~A}_{\mathrm{g}}^{-}\right)\right)$. As a result, the carotenoid steady state absorption surfaces in the blue-green part of the visible spectrum, stemming from the optically allowed transitions to a short-lived higher excited singlet state $\mathrm{S}_{2}\left(\mathrm{~S}_{0}\left(1^{1} \mathrm{~A}_{\mathrm{g}}^{-}\right) \rightarrow \mathrm{S}_{2}\left(1^{1} \mathrm{~B}_{\mathrm{u}}^{+}\right)\right)$. In less than hundred femtoseconds $S_{2}$ decays to the longer lived $S_{1}$, with a small portion of the $S_{2}$ population typically experiencing stimulated emission back to $S_{0}$ [56]. Carotenoids exhibit very intense Raman scattering signals both in the ground state and the excited state, thus making them perfect targets for FSRS analysis.

$\beta$-carotene needs little introduction, owing to its excessive natural abundance in plants and fruit and its importance to the nutrition of humans and other animals [57]. $\beta$-carotene has already been subjected to multiple FSRS studies [8, 12, 48, 58]. The well-documented nature of $\beta$-carotene FSRS (and infrared [59, 60]) dynamics makes it a great archetypal candidate for evaluating the performance of the presented FSRS setup. The $S_{\rightarrow} \rightarrow S_{n}$ transient absorption of $\beta$-carotene peaks in the nIR [61], whereas the $S_{1} \rightarrow S_{n}$ transient absorption reaches its maximum at ca. $450 \mathrm{~nm}$ [62]. The vibrational constitution and the transition between the $1^{1} \mathrm{~B}_{\mathrm{u}}^{+}$and $2^{1} \mathrm{~A}_{\mathrm{g}}^{-}$states can be monitored by using different Raman pump wavelengths. For the FSRS experiments $\beta$-carotene (Sigma-Aldrich 22040) was dissolved in $n$-hexane (Rotisolv, HPLC grade) and diluted to optical density of 1 at $490 \mathrm{~nm}$ in a $1 \mathrm{~mm}$ optical pathway. $\mathrm{S}_{0} \rightarrow \mathrm{S}_{2}$ excitation was performed by using $\lambda_{\text {act }}=490 \mathrm{~nm}, E_{\text {act }}=150 \mathrm{~nJ}$, $\tau_{\text {act }}=70$ fs ultrashort pulses, while the Raman pump pulses were set to either $\lambda_{\mathrm{RP}}=550 \mathrm{~nm}, E_{\mathrm{RP}}=500 \mathrm{~nJ}$, $\tau_{\mathrm{RP}}=3 \mathrm{ps} ;$ or $\lambda_{\text {exc }}=615 \mathrm{~nm}, E_{\text {exc }}=2 \mu \mathrm{J}, \tau_{\mathrm{RP}}=6.5 \mathrm{ps}$.

The $\mathrm{S}_{\rightarrow} \rightarrow \mathrm{S}_{n}$ absorption peaks at ca. $950 \mathrm{~nm}$ in $n$ hexane [61], albeit application of such a Raman pump (or even a proximate one) is near impossible due to spectral sensitivity limitations of the silicon-based CCD arrays: the Stokes-shifted wavelengths will be at or beyond the edge of the upper sensitivity limit (ca. $1100 \mathrm{~nm}$ ). In order to have the FSRS signals within the detectable wavelength range, we have utilized a $790 \mathrm{~nm}$ Raman pump. These Raman pump pulses are primarily resonant with the $S_{2} \rightarrow S_{n}$ transitions [61], albeit the low-intensity long-wave tail of the $S_{\rightarrow} \rightarrow S_{n}$ absorption extends beyond the visible spectrum [62], hence making the $790 \mathrm{~nm}$ Raman pump partly resonant with both the $\mathrm{S}_{2} \rightarrow \mathrm{S}_{n}$ and $\mathrm{S}_{1} \rightarrow \mathrm{S}_{n}$ electronic transitions. The formation of the $S_{2}$ state can be best observed in Fig. 5(a), where the sub-500-femtosecond 

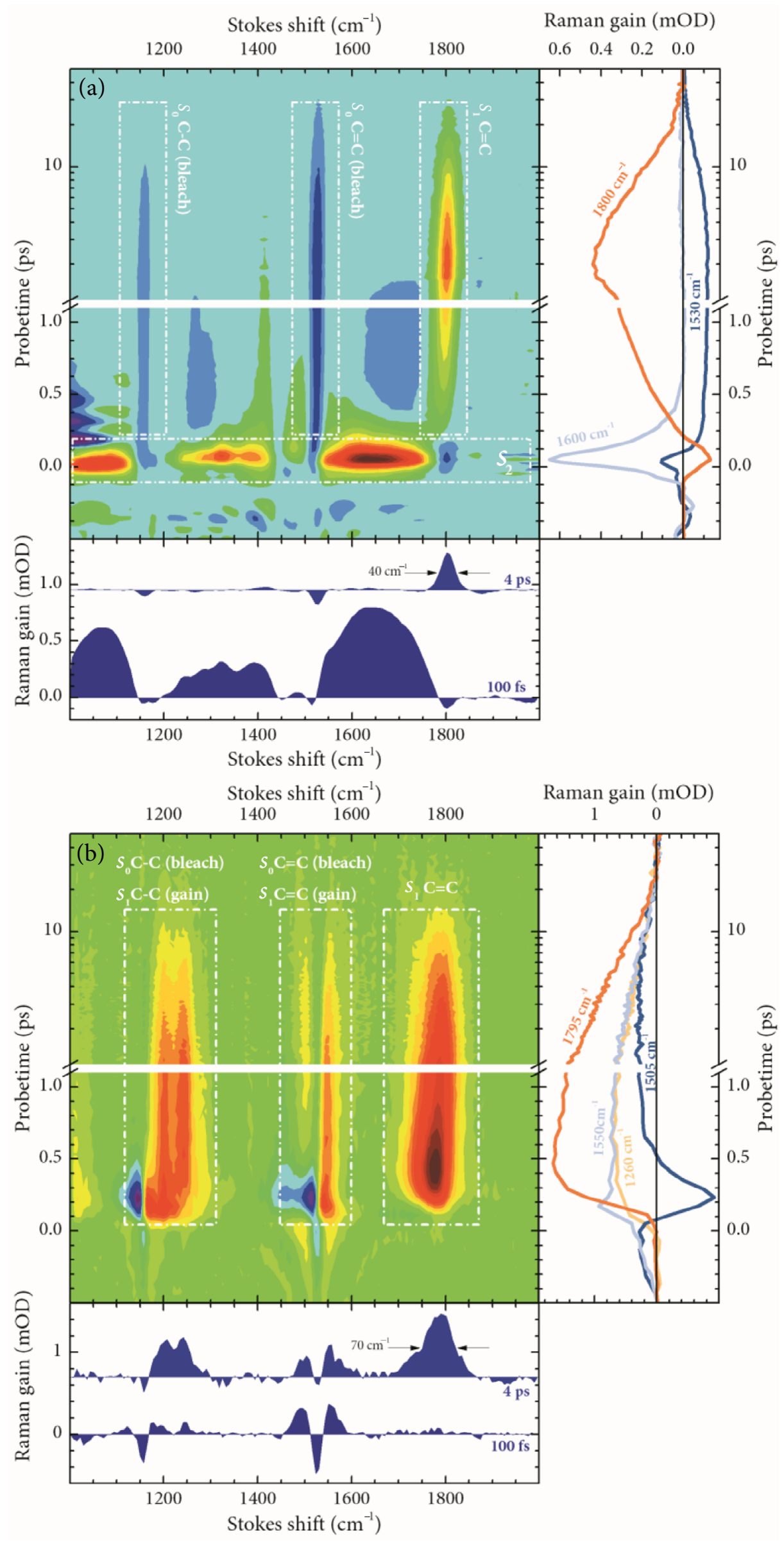

Fig. 5. FSRS dynamics of $\beta$-carotene in $n$-hexane, obtained by using a $790 \mathrm{~nm}$ (a) and $550 \mathrm{~nm}$ (b) Raman pump. The central panels depict the entire time and wavenumber-resolved FSRS spectrum, whereas the right-hand side and bottom graphs accentuate several selected spectral and temporal cuts of the FSRS datamap. Certain regions of interest are highlighted and annotated in the main FSRS graphs. 
photoevolution reveals an emergence of a distinct three-band structure, peaking at ca. 1070, 1350, and $1640 \mathrm{~cm}^{-1}$. These peak clusters (that have been decomposed into seven discrete Gaussian peaks in a study by Kukura et al. [12]) have been previously identified as the $\mathrm{S}_{2}$ vibrational spectrum. This multi-peak conformation decays within the first few hundred femtoseconds (once again, mirroring the results in Ref. [12]), gradually leading to the formation of $S_{1}$. Since $S_{1}$ is only weakly resonant with the $790 \mathrm{~nm}$ Raman pump, only the most intense $\mathrm{S}_{1}$ vibration - the high-frequency $\mathrm{C}=\mathrm{C}$ stretching at $\mathrm{ca}$. $1800 \mathrm{~cm}^{-1}$ - appears in the sub-100-ps FSRS spectrum of $\beta$-carotene $[12,59,60]$. As evident in Fig. 5, the particular mode demonstrates a peak-shift (to higher frequencies) and spectral narrowing during the first few picoseconds that can be ascribed to the initial formation of a hot $S_{1}$ intermediate and its eventual vibrational cooling [8]. Other indications of a molecular system, not yet fully restored to a thermal equilibrium, show up as the negative bleaching of the two ground state resonances, i. e. the negative peaks at $1159 \mathrm{~cm}^{-1}$ (depletion of the $S_{0}$ $\mathrm{C}-\mathrm{C}$ stretching mode [63]) and $1526 \mathrm{~cm}^{-1}$ (depletion of the $\mathrm{S}_{0} \mathrm{C}=\mathrm{C}$ stretching mode [63]).

The $550 \mathrm{~nm}$ Raman pump, in contrast, falls directly under the $S_{1} \rightarrow S_{n}$ absorption maximum, hence all of the positive (i. e. FSRS gain) features in Fig. 5(b) can be ascribed exclusively to the $S_{1}$ manifold. It is obvious that the broadband multipeak structure is not present in Fig. 5(b) during the initial steps of the post-excitation vibrational evolution, and is instead replaced by the gradual formation of the $\mathrm{S}_{1}$-indicative vibrational peaks. The intense $\mathrm{C}=\mathrm{C}$ vibrations at ca. $1800 \mathrm{~cm}^{-1}$ similarly dominate within the $S_{1}$ vibrational photodynamics, and likewise demonstrate the peak-shift and band-narrowing spectrodynamics, associated with vibrational cooling. In contrast to the $790 \mathrm{~nm}$ experiments, the FSRS spectra in Fig. 5(b) feature two additional spectral bands that prevail throughout the entire $\mathrm{S}_{1}$ lifetime: the ca. $1240 \mathrm{~cm}^{-1} \mathrm{~S}_{1} \mathrm{C}-\mathrm{C}$ stretching mode, and the low-frequency $\mathrm{S}_{1} \mathrm{C}=\mathrm{C}$ vibrations at ca. $1550 \mathrm{~cm}^{-1}$ [1]. The latter band lies close to the hot $S_{0}$ peak at $1510 \mathrm{~cm}^{-1}[11]$, that slowly develops in a sub-20-picosecond temporal interval (see Fig. 5(b)). Both the $S_{1}$ spectral peaks arise near their corresponding (yet bleached) ground state positions, thus giving the FSRS time-gated spectra a distinctive cleft-like profile (which can be patched-up by the addition of a scaled ground state Raman spectrum [12]). The vibrational peaks in Fig. 5(b) are notably broader (up to $75 \%$ at FWHM) than their equivalents in Fig. E(a) (the previously reported values of the $\mathrm{S}_{1} \mathrm{C}=\mathrm{C}$ bandwidth were ca. $50 \mathrm{~cm}^{-1}$ ) [8]. Recognizing that the spectral detection resolution is essentially identical in both the experiments $\left(\bar{v}_{\mathrm{VIS}}=6.5 \mathrm{~cm}^{-1}\right.$ with a $1200 \mathrm{~mm}^{-1}$ grating in the visible, and $\bar{v}_{\mathrm{nIR}}=7 \mathrm{~cm}^{-1}$ with a $600 \mathrm{~mm}^{-1}$ grating in the nIR), the spectral broadening in the $540 \mathrm{~nm}$ Raman pump measurements is most likely instigated by either (a) Raman line bandwidth dependence on the resonant enhancement conditions; (b) a relatively larger bandwidth of the VIS Raman pump $\left(\tau_{\mathrm{RP}}^{\mathrm{VIS}} / \tau_{\mathrm{RP}}^{\mathrm{nIR}} \approx 2.2\right)$; or (c) the possible influence of "parasitic" band-widening $\chi^{(5)}$ signals, such as hot luminescence $[31,64,65]$.

Disregarding the intrinsic differences between the two FSRS spectra in Fig. 5 , it is obvious that they both paint an equally informative photoevolutionary picture: the most significant development steps, i. e. population and depopulation of the $\mathrm{S}_{2}$ state, its sub-picosecond decay into the hot $S_{1}$ manifold, the latter state's vibrational cooling and eventual decay to the main ground state, can be inferred from either one of the FSRS datasets. In conclusion, we can see that, contrary to typical pump-probe experiments, FSRS offers much constructive information on the vibrational structure of the excited state spectrum. The easy tunability of the presented FSRS setup allows us to suggest its application in future 2D FSRS measurements. As depicted in Fig. 6, continuously scanning the Raman pump over a wide spectral range (essentially, covering the bulk of the electronic transient absorption spectrum) would provide us with two-dimensional FSRS data $S\left(v_{\text {Pump }}, v_{\text {Probe }}, \tau\right)$. This kind of FSRS mapping would, expectedly, shed additional insight on the constitution of the electronic states, their mutual interaction, and the possible coupling between them. Raman spectra emerging at different Raman pump wavelengths could be used as a basis in disentangling and attributing overlapping bands observed in pump-probe spectra. In this way, the excellent time resolution and accurate dynamic information of electronic pump-probe spectroscopy (note that pump-probe data come as a "byproduct" of this implementation of the FSRS setup) would be complemented by the structural sensitivity and selectivity of Raman signals. We predict that this type of experiments could be easily carried out on such carotenoid-containing photosynthetic systems as peridinin chlorophyll protein (PCP) [66] and fucoxanthin chlorophyll protein (FCP) [67] to uncover the interplay between the internal charge transfer bearing carbonyl-carotenoids and the chlorophylls, or to gain more understanding on the dark states of carotenoids [68-70]. 


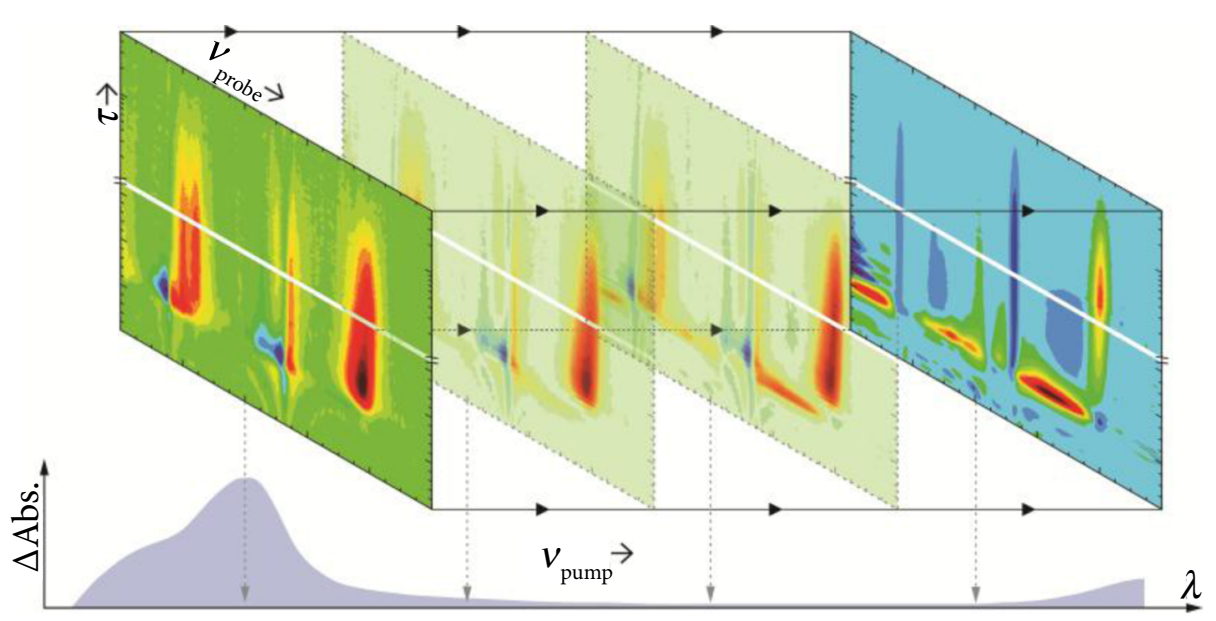

Fig. 6. Proposed scheme of a 2D FSRS experiment: the Raman pump is scanned through the transient absorption profile, measuring a series of FSRS spectra, thus providing time-, wavenumber-, and excitation wavenumber-resolved FSRS data.

\section{Conclusions}

In this work we have demonstrated an economic homebuilt FSRS apparatus, capable of time-resolved measurements with a spectral resolution of $\Delta v \leq 6 \mathrm{~cm}^{-1}$, a temporal resolution of $\Delta \tau \leq 70 \mathrm{fs}$, and a resolvable spectral bandwidth of up to ca. $3000 \mathrm{~cm}^{-1}$. Tunability of the narrowband (up to ca. $1.5 \mathrm{~cm}^{-1}$ ) Raman pump pulses are produced by generating and spectrally filtering the second harmonic of a high-power optical parametric amplifier output, and can be implemented in the 400-800 $\mathrm{nm}$ region. Time-resolved vibrational dynamics of $\beta$-carotene $\mathrm{S}_{2}\left(1^{1} \mathrm{~B}_{\mathrm{u}}^{+}\right)$and $\mathrm{S}_{1}\left(2^{1} \mathrm{~A}_{\mathrm{g}}^{-}\right)$states are presented as a functional example of the FSRS setup. The setup simultaneously measures pump-probe and FSRS signals and allows combining excellent dynamic resolution and signal-to-noise of the former with the structural sensitivity of the latter. Easy tunability of the Raman pump wavelength opens up a possibility of measuring 2D FSRS spectra for the detailed exploration of the dynamic excited state manifolds in photoactive molecules.

\section{References}

[1] P. Stoutland, R. Dyer, and W. Woodruff, Ultrafast infrared spectroscopy, Science 257(5078), 19131917 (1992).

[2] M.D. Fayer, Ultrafast Infrared and Raman Spectroscopy (CRC Press, New York, USA, 2001).

[3] J. Knorr, P. Rudolf, and P. Nuernberger, A comparative study on chirped-pulse upconversion and direct multichannel MCT detection, Opt. Express 21(25), 30693-30706 (2013).

[4] C.R. Baiz and K.J. Kubarych, Ultrabroadband detection of a mid-IR continuum by chirped-pulse upconversion, Opt. Lett. 36(2), 187-189 (2011).

[5] P. Kukura, D.W. McCamant, and R.A. Mathies, Femtosecond stimulated Raman spectroscopy, Annu. Rev. Phys. Chem. 58(1), 461-488 (2007).
[6] D.W. McCamant, P. Kukura, and R.A. Mathies, Femtosecond broadband stimulated Raman: a new approach for high-performance vibrational spectroscopy, Appl. Spectrosc. 57(11), 1317-1323 (2003).

[7] D.W. McCamant, P. Kukura, S. Yoon, and R.A. Mathies, Femtosecond broadband stimulated Raman spectroscopy: Apparatus and methods, Rev. Sci. Instrum. 75(11), 4971-4980 (2004).

[8] D.W. McCamant, P. Kukura, and R.A. Mathies, Femtosecond time-resolved stimulated Raman spectroscopy: Application to the ultrafast internal conversion in $\beta$-carotene, J. Phys. Chem. A 107(40), 8208-8214 (2003).

[9] H. Kuramochi, S. Takeuchi, and T. Tahara, Ultrafast structural evolution of photoactive yellow protein chromophore revealed by ultraviolet resonance femtosecond stimulated Raman spectroscopy, J. Phys. Chem. Lett. 3(15), 2025-2029 (2012).

[10]C. Fang, R.R. Frontiera, R. Tran, and R.A. Mathies, Mapping GFP structure evolution during proton transfer with femtosecond Raman spectroscopy, Nature 462(7270), 200-204 (2009).

[11]S. Shim and R.A. Mathies, Development of a tunable femtosecond stimulated Raman apparatus and its application to $\beta$-carotene, J. Phys. Chem. B 112(15), 4826-4832 (2008).

[12]P. Kukura, D.W. McCamant, and R.A. Mathies, Femtosecond time-resolved stimulated Raman spectroscopy of the $\mathrm{S}_{2}\left(1 \mathrm{~B}_{\mathrm{u}}^{+}\right)$excited state of $\beta$-carotene, J. Phys. Chem. A 108(28), 5921-5925 (2004).

[13]D.W. McCamant, P. Kukura, and R.A. Mathies, Femtosecond stimulated Raman study of excitedstate evolution in bacteriorhodopsin, J. Phys. Chem. B 109(20), 10449-10457 (2005).

[14]S. Frobel, L. Buschhaus, T. Villnow, O. Weingart, and P. Gilch, The photoformation of a phthalide: a ketene intermediate traced by FSRS, Phys. Chem. Chem. Phys. 17(1), 376-386 (2015).

[15]D.P. Hoffman and R.A. Mathies, Photoexcited structural dynamics of an azobenzene analog 4-nitro-4 
[prime or minute]-dimethylamino-azobenzene from femtosecond stimulated Raman, Phys. Chem. Chem. Phys. 14(18), 6298-6306 (2012).

[16]A.L. Dobryakov, I. Ioffe, A.A. Granovsky, N.P. Ernsting, and S.A. Kovalenko, Femtosecond Raman spectra of cis-stilbene and trans-stilbene with isotopomers in solution, J. Chem. Phys. 137(24), 244505 (2012).

[17]A.L. Smeigh, M. Creelman, R.A. Mathies, and J.K. McCusker, Femtosecond time-resolved optical and Raman spectroscopy of photoinduced spin crossover: temporal resolution of low-to-high spin optical switching, J. Am. Chem. Soc. 130(43), 14105-14107 (2008).

[18]S. Yoon, P. Kukura, C.M. Stuart, and R.A. Mathies, Direct observation of the ultrafast intersystem crossing in tris(2,2'-bipyridine)ruthenium(II) using femtosecond stimulated Raman spectroscopy, Mol. Phys. 104(8), 1275-1282 (2006).

[19]T. Fujisawa, M. Creelman, and R.A. Mathies, Structural dynamics of a noncovalent charge transfer complex from femtosecond stimulated Raman spectroscopy, J. Phys. Chem. B 116(35), 1045310460 (2012).

[20] K.E. Brown, B.S. Veldkamp, D.T. Co, and M.R. Wasielewski, Vibrational dynamics of a perylene-perylenediimide donor-acceptor dyad probed with femtosecond stimulated Raman spectroscopy, J. Phys. Chem. Lett. 3(17), 2362-2366 (2012).

[21]R.M. Young, S.M. Dyar, J.C. Barnes, M. Juríček, J.F. Stoddart, D.T. Co, and M.R. Wasielewski, Ultrafast conformational dynamics of electron transfer in $\mathrm{ExBox}^{4+} \subset$ perylene, J. Phys. Chem. A 117(47), 12438-12448 (2013).

[22]E.M. Grumstrup, Z. Chen, R.P. Vary, A.M. Moran, K.S. Schanze, and J.M. Papanikolas, Frequency modulated femtosecond stimulated Raman spectroscopy of ultrafast energy transfer in a donor-acceptor copolymer, J. Phys. Chem. B 117(27), 82458255 (2013).

[23]R.R. Frontiera and R.A. Mathies, Polarization dependence of vibrational coupling signals in femtosecond stimulated Raman spectroscopy, J. Chem. Phys. 127(12), 124501 (2007).

[24]S. Shim and R.A. Mathies, Femtosecond Ramaninduced Kerr effect spectroscopy, J. Raman Spectrosc. 39(11), 1526-1530 (2008).

[25]R.R. Frontiera, A.-I. Henry, N.L. Gruenke, and R.P. Van Duyne, Surface-enhanced femtosecond stimulated Raman spectroscopy, J. Phys. Chem. Lett. 2(10), 1199-1203 (2011).

[26]D.P. Hoffman, S.R. Ellis, and R.A. Mathies, Characterization of a conical intersection in a chargetransfer dimer with two-dimensional time-resolved stimulated Raman spectroscopy, J. Phys. Chem. A 118(27), 4955-4965 (2014).

[27]D.T. Valley, D.P. Hoffman, and R.A. Mathies, Reactive and unreactive pathways in a photo- chemical ring opening reaction from $2 \mathrm{D}$ femtosecond stimulated Raman, Phys. Chem. Chem. Phys. 17(14), 9231-9240 (2015).

[28]B. Dunlap, P. Richter, and D.W. McCamant, Stimulated Raman spectroscopy using chirped pulses, J. Raman Spectrosc. 45(10), 918-929 (2014).

[29]K.E. Dorfman, F. Schlawin, and S. Mukamel, Stimulated Raman spectroscopy with entangled light: enhanced resolution and pathway selection, J. Phys. Chem. Lett. 5(16), 2843-2849 (2014).

[30]R.R. Frontiera, C. Fang, J. Dasgupta, and R.A. Mathies, Probing structural evolution along multidimensional reaction coordinates with femtosecond stimulated Raman spectroscopy, Phys. Chem. Chem. Phys. 14(2), 405-414 (2012).

[31]B. Zhao, K. Niu, X. Li, and S.-Y. Lee, Simple aspects of femtosecond stimulated Raman spectroscopy, Sci. China Chem. 54(12), 1989-2008 (2011).

[32]W. Rock, Y.-L. Li, P. Pagano, and C.M. Cheatum, 2D IR spectroscopy using four-wave mixing, pulse shaping, and IR upconversion: a quantitative comparison, J. Phys. Chem. A 117(29), 6073-6083 (2013).

[33]W.R. Silva, E.L. Keller, and R.R. Frontiera, Determination of resonance Raman cross-sections for use in biological SERS sensing with femtosecond stimulated Raman spectroscopy, Anal. Chem. 86(15), 7782-7787 (2014).

[34]D. Verreault, V. Kurz, C. Howell, and P. Koelsch, Sample cells for probing solid/liquid interfaces with broadband sum-frequency-generation spectroscopy, Rev. Sci. Instrum. 81(6), 063111 (2010).

[35] M.J. Nee, R. McCanne, K.J. Kubarych, and M. Joffre, Two-dimensional infrared spectroscopy detected by chirped pulse upconversion, Opt. Lett. 32(6), 713-715 (2007).

[36]J. Zhu, T. Mathes, A.D. Stahl, J.T.M. Kennis, and M.L. Groot, Ultrafast mid-infrared spectroscopy by chirped pulse upconversion in $1800-1000 \mathrm{~cm}^{-1} \mathrm{re}-$ gion, Opt. Express 20(10), 10562-10571 (2012).

[37]W. Yu, P.J. Donohoo-Vallett, J. Zhou, and A.E. Bragg, Ultrafast photo-induced nuclear relaxation of a conformationally disordered conjugated polymer probed with transient absorption and femtosecond stimulated Raman spectroscopies, J. Chem. Phys. 141(4), 044201 (2014).

[38]A. Weigel and N.P. Ernsting, Excited stilbene: intramolecular vibrational redistribution and solvation studied by femtosecond stimulated Raman spectroscopy, J. Phys. Chem. B 114(23), 7879-7893 (2010).

[39]S.A. Kovalenko, A.L. Dobryakov, and N.P. Ernsting, An efficient setup for femtosecond stimulated Raman spectroscopy, Rev. Sci. Instrum. 82(6), 063102 (2011).

[40]L. Zhu, W. Liu, and C. Fang, A versatile femtosecond stimulated Raman spectroscopy setup with tunable pulses in the visible to near infrared, Appl. Phys. Lett. 105(4), 041106 (2014). 
[41]Light Conversion TOPAS-800, http://www.lightcon. com/upload/iblock/29d/29d33cd94596711304f676 b78bc85064.pdf accessed: 14/10/2015.

[42] M.A. Marangoni, D. Brida, M. Quintavalle, G. Cirmi, F.M. Pigozzo, C. Manzoni, F. Baronio, A.D. Capobianco, and G. Cerullo, Narrowbandwidth picosecond pulses by spectral compression of femtosecond pulses in second-order nonlinear crystals, Opt. Express 15(14), 88848891 (2007).

[43]E. Pontecorvo, C. Ferrante, C.G. Elles, and T. Scopigno, Spectrally tailored narrowband pulses for femtosecond stimulated Raman spectroscopy in the range 330-750 nm, Opt. Express 21(6), 6866-6872 (2013).

[44]V.G. Dmitriev, G.G. Gurzadyan, and D.N. Nikogosyan, Handbook of Nonlinear Optical Crystals (Springer, Berlin, Germany, 1999).

[45]E. Pontecorvo, S.M. Kapetanaki, M. Badioli, D. Brida, M. Marangoni, G. Cerullo, and T. Scopigno, Femtosecond stimulated Raman spectrometer in the 320-520 nm range, Opt. Express 19(2), 1107-1112 (2011).

[46]D.P. Hoffman, O.P. Lee, J.E. Millstone, M.S. Chen, T.A. Su, M. Creelman, J.M.J. Fréchet, and R.A. Mathies, Electron transfer dynamics of triphenylamine dyes bound to $\mathrm{TiO}_{2}$ nanoparticles from femtosecond stimulated Raman spectroscopy, J. Phys. Chem. C 117(14), 6990-6997 (2013).

[47]F. Han, W. Liu, and C. Fang, Excited-state proton transfer of photoexcited pyranine in water observed by femtosecond stimulated Raman spectroscopy, Chem. Phys. 422(0), 204-219 (2013).

[48]M. Kloz, R. van Grondelle, and J.T.M. Kennis, Wavelength-modulated femtosecond stimulated Raman spectroscopy - approach towards automatic data processing, Phys. Chem. Chem. Phys. 13(40), 18123-18133 (2011).

[49]A. Weigel, A. Dobryakov, B. Klaumünzer, M. Sajadi, P. Saalfrank, and N.P. Ernsting, Femtosecond stimulated Raman spectroscopy of flavin after optical excitation, J. Phys. Chem. B 115(13), 3656-3680 (2011).

[50]S. Laimgruber, H. Schachenmayr, B. Schmidt, W. Zinth, and P. Gilch, A femtosecond stimulated Raman spectrograph for the near ultraviolet, Appl. Phys. B 85(4), 557-564 (2006).

[51]H. Ando, B.P. Fingerhut, K.E. Dorfman, J.D. Biggs, and S. Mukamel, Femtosecond stimulated Raman spectroscopy of the cyclobutane thymine dimer repair mechanism: a computational study, J. Am. Chem. Soc. 136(42), 14801-14810 (2014).

[52]J.R. Ferraro, K. Nakamoto, and C.W. Brown, Introductory Raman Spectroscopy (Academic Press, Amsterdam, The Netherlands, 2003).

[53]J. Dasgupta, R.R. Frontiera, K.C. Taylor, J.C. Lagarias, and R.A. Mathies, Ultrafast excited-state isomerization in phytochrome revealed by femto- second stimulated Raman spectroscopy, Proc. Natl. Acad. Sci. USA 106(6), 1784-1789 (2009).

[54]H.A. Frank and R.J. Cogdell, Carotenoids in photosynthesis, Photochem. Photobiol. 63(3), 257-264 (1996).

[55]B. Demmig-Adams and W.W. Adams III, The role of xanthophyll cycle carotenoids in the protection of photosynthesis, Trends Plant Sci. 1(1), 21-26 (1996).

[56]Y. Koyama, M. Kuki, P.O. Andersson, and T. Gillbro, Singlet excited states and the light-harvesting function of carotenoids in bacterial photosynthesis, Photochem. Photobiol. 63(3), 243-256 (1996).

[57]A. Young and G. Britton, Carotenoids in Photosynthesis (Springer Science \& Business Media, Dordrecht, The Netherlands, 1993).

[58]M. Kloz, R. van Grondelle, and J.T.M. Kennis, Correction for the time dependent inner filter effect caused by transient absorption in femtosecond stimulated Raman experiment, Chem. Phys. Lett. 544, 94-101 (2012).

[59]T. Noguchi, S. Kolaczkowski, C. Arbour, S. Aramaki, G.H. Atkinson, H. Hayashi, and M. Tasumi, Resonance Raman spectrum of the excited $2^{1} \mathrm{Ag}$ state of $\beta$-carotene, Photochem. Photobiol. 50(5), 603-609 (1989).

[60]D.W. McCamant, J.E. Kim, and R.A. Mathies, Vibrational relaxation in $\beta$-carotene probed by picosecond Stokes and anti-Stokes resonance Raman spectroscopy, J. Phys. Chem. A 106(25), 6030-6038 (2002).

[61]J.-P. Zhang, L.H. Skibsted, R. Fujii, and Y. Koyama, Transient absorption from the $1 \mathrm{~B}_{\mathrm{u}}^{+}$state of alltrans- $\beta$-carotene newly identified in the near-infrared region, Photochem. Photobiol. 73(3), 219-222 (2001).

[62]D.S. Larsen, E. Papagiannakis, I.H.M. van Stokkum, M. Vengris, J.T.M. Kennis, and R. van Grondelle, Excited state dynamics of $\beta$-carotene explored with dispersed multi-pulse transient absorption, Chem. Phys. Lett. 381(5-6), 733-742 (2003).

[63]H. Hashimoto, Y. Koyama, Y. Hirata, and N. Mataga, $\mathrm{S}_{1}$ and $\mathrm{T}_{1}$ species of $\beta$-carotene generated by direct photoexcitation from the all-trans, 9-cis, 13-cis, and 15-cis isomers as revealed by picosecond transient absorption and transient Raman spectroscopies, J. Phys. Chem. 95(8), 3072-3076 (1991).

[64]R.R. Frontiera, S. Shim, and R.A. Mathies, Origin of negative and dispersive features in anti-Stokes and resonance femtosecond stimulated Raman spectroscopy, J. Chem. Phys. 129(6), 064507 (2008).

[65]Z. Sun, Z. Jin, J. Lu, D.H. Zhang, and S.-Y. Lee, Wave packet theory of dynamic stimulated Raman spectra in femtosecond pump-probe spectroscopy, J. Chem. Phys. 126(17), 174104 (2007).

[66]D. Zigmantas, R.G. Hiller, V. Sundström, and T. Polívka, Carotenoid to chlorophyll energy transfer in the peridinin-chlorophyll- $a$-protein complex 
involves an intramolecular charge transfer state, Proc. Natl. Acad. Sci. USA 99(26), 16760-16765 (2002).

[67]V. Butkus, A. Gelzinis, R. Augulis, A. Gall, C. Büchel, B. Robert, D. Zigmantas, L. Valkunas, and D. Abramavicius, Coherence and population dynamics of chlorophyll excitations in FCP complex: Two-dimensional spectroscopy study, J. Chem. Phys. 142(21), 212414 (2015).

[68] E. Papagiannakis, J.T.M. Kennis, I.H.M. van Stokkum, R.J. Cogdell, and R. van Grondelle, An alter- native carotenoid-to-bacteriochlorophyll energy transfer pathway in photosynthetic light harvesting, Proc. Natl. Acad. Sci. USA 99(9), 6017-6022 (2002).

[69]T. Polívka and V. Sundström, Dark excited states of carotenoids: Consensus and controversy, Chem. Phys. Lett. 477(1-3), 1-11 (2009).

[70]E.E. Ostroumov, M.G.M.M. Reus, and A.R. Holzwarth, On the nature of the "dark $S^{\star "}$ excited state of $\beta$-carotene, J. Phys. Chem. A 115(16), 3698-3712 (2011).

\title{
DERINAMO DAŽNIO FEMTOSEKUNDINĖ PRIVERSTINĖS RAMANO SKLAIDOS SISTEMA, PAGRİSTA SPEKTRIŠKAI SUSIAURINTOS ANTROSIOS HARMONIKOS GENERAVIMU
}

\author{
K. Redeckas, V. Voiciuk, M. Vengris \\ Vilniaus universiteto Kvantines elektronikos katedra, Vilnius, Lietuva
}

\section{Santrauka}

Darbe pristatome femtosekundinę priverstinès Ramano sklaidos sistemą. Pirminis eksperimente naudojamų impulsų šaltinis yra komercinè femtosekundinè lazeriné sistema, kaupinanti du bėgančios bangos optinius parametrinius stiprintuvus. Vienas iš optinių parametrinių stiprintuvų naudojamas derinamų parametrinių stiprintuvų femtosekundiniams žadinantiesiems impulsams generuoti. Kito (didelès išvadinès galios) optinio parametrinio stiprintuvo spinduliuotè nukreipiama ì ilgą netiesini kristalą ir $4 f$ spektrinio filtravimo sistemą, taip formuojant siaurajuosčius (pikosekundinius) Ramano sklaidos žadinimo impulsus. Plačiajuostis baltos šviesos superkontinuumas naudojamas zonduojant priverstinę Ramano sklaidą. Tokia eksperimentinè konfigūracija leidžia generuoti Ramano sklaidos žadinimo impulsus 400$800 \mathrm{~nm}$ diapazone ir pasiekti $\sim 6 \mathrm{~cm}^{-1}$ spektrinę bei $\sim 70 \mathrm{fs}$ laikinę skyras. Šiame darbe mes apžvelgiame techninę šios matavimo sistemos dalị, jos optinę konfigūraciją bei pagrindinius spektrinių signalų registravimo ir rekonstrukcijos aspektus. Sistemai charakterizuoti ir jos galimybėms pristatyti mes pateikiame $\beta$-karoteno sužadintujjų būsenų $\mathrm{S}_{2}\left(1^{1} \mathrm{~B}_{\mathrm{u}}^{+}\right)$ir $\mathrm{S}_{1}\left(2^{1} \mathrm{~A}_{\mathrm{g}}^{-}\right)$laikinès skyros tyrimus. 